\title{
Spatially Explicit Analysis of Biodiversity Loss due to Global Agriculture, Pasture and Forest Land Use from a Producer and Consumer Perspective
}

\author{
Abhishek Chaudhary ${ }^{1 *}$, Stephan Pfister ${ }^{1}$ and Stefanie Hellweg ${ }^{1}$ \\ 1 Institute of Environmental Engineering, ETH Zurich, 8093 Zurich, Switzerland, \\ $\left({ }^{*}\right.$ Corresponding author phone: 41-44-6330254; fax: 41-44-6331061; e-mail: \\ abhishek@ifu.baug.ethz.ch)
}

\section{Supplementary Information-1}

This file includes

SI Text pages S1-S9

Figure S1-S3

\section{Table of Contents:}

Part A: Additional Methods
A1). Global characterization factors (CFs) at ecoregion level
A2). Taxa aggregated characterization factors

\section{Part B: Additional results}

- Figure S1. Biodiversity impacts per taxa (Species eq. lost*years) at 5 arc minute resolution due to global agriculture land use.

- Figure S2. Biodiversity impacts per taxa (Species eq. lost*years) at 5 arc minute resolution due to global pasture land use.

- Figure S3. Biodiversity impacts per taxa (Species eq. lost*years) at 5 arc minute resolution due to global forest land use.

\section{Part C: References}


A1). Global characterization factors (CFs) at ecoregion level

Equation S1

Here $A_{\text {new }}$ is the remaining natural habitat area in the ecoregion, $A_{i}$ is the area of individual land use type $i, z$ is the SAR exponent, and $h_{g, i, j}$ is the affinity of taxa $g$ to the land use type $i$. Affinity value for natural habitat is 1 and decreases till zero as the land use becomes more hostile to the species.

Next, the total species loss per ecoregion calculated using equation S1 due to total land use is allocated to each land use type $i$ according to their relative area share and the taxa affinity to them through an allocation factor $a_{i, j} \cdot{ }^{1,3}$ Finally, the land occupation CFs for each taxa $g$, land use type $i$ in an ecoregion $j$ are calculated as:

$$
C F_{\text {regional }, g, i, j}=\frac{S_{\text {lost }, g, j, t o t a l} * a_{i, j}}{A_{\text {lost }, j}}
$$

CFs in equation S2 give an estimate of regional species lost per m² of six different land use typesi CFs in equation S2 give an estimate of regional species lost per $\mathrm{m}^{2}$ of six different land use types $i$ (annual crops, permanent crops, pasture, urban, extensive forestry, intensive forestry). The regional CFs are then multiplied with vulnerability score of each taxon in each ecoregion $\left(V S_{g, j}\right)$ to calculate global CFs in the unit - global species equivalents lost per $\mathrm{m}^{2}$ (hereafter species eq. lost $\left./ m^{2}\right):{ }^{1}$

$$
C F_{\text {global,g } i, j}=C F_{\text {regional }, g, i, j} \cdot V S_{g, j}
$$


The vulnerability score ranges between 0 and 1 and is defined as threat level weighted ratio of 'endemic richness' to total species richness within an ecoregion. The VS value reaches 1 if all species within a region have $100 \%$ of their range inside it (i.e. strictly endemic) and are listed as 'critically endangered' by IUCN red list.1,4

In LCA, the occupation CFs from equation S3 are multiplied by the inventory flow of occupation given in $\mathrm{m}^{2}$.years to obtain the biodiversity damage $\left(B D_{g, i, j}\right)$ in units of species eq. lost.years for each taxonomic group g.1,4 In this study, we imported the global CFs from supporting information-2 excel file to the article Chaudhary et al. ${ }^{1}$

\section{A2). Taxa Aggregated characterization factors}

As LCA practitioners might be overwhelmed by four characterization factors (CFs) per land use type, Chaudhary et al. ${ }^{1}$ also provide taxa-aggregated CFs for each land use type. The global CFs are aggregated across four taxa according to: ${ }^{1}$

$$
C F_{\text {aggwgt }, i, j}=\frac{1}{4} \sum_{g=1}^{4} \frac{C F_{\text {global }, g, i, j}}{S_{t o t, g} \cdot V S_{g, w o r l d}}
$$

Where $C F_{\text {global,g,i,j }}$ is the global CF for taxa $g$ calculated using equation S3 above, $S_{t o t, g}$ is the total number of species in each taxonomic group for which the range maps were available from IUCN and is equal to 5386 for mammals, 10'104 for birds, 3384 for reptiles, and 6251 for amphibians. $V S_{g, \text { world }}$ is the world average vulnerability score for taxa $g$ and is calculated from vulnerability scores of individual ecoregion $j\left(V S_{g, j}\right)$ and the species richness $S_{\text {org,g,j}}$ :

$$
V S_{g, w o r l d}=\frac{\sum_{j=1}^{804} V S_{g, j} \cdot S_{\text {org }, g, j}}{S_{t o t, g}}
$$

$V S_{g, \text { world }}$ values were calculated as 0.29 for birds, 0.44 for mammals, 0.59 for amphibians and 0.46 for reptiles. ${ }^{1}$ Note that other aggregation options do exist and it is a matter of value choice (see Verones et al. ${ }^{5}$ for more discussion on taxa-aggregation options). 
81 Figure S1. Biodiversity impacts per taxa (Species eq. lost*years) at 5 arc minute resolution due to global agriculture land use, calculated using equation-1 of main text. level.

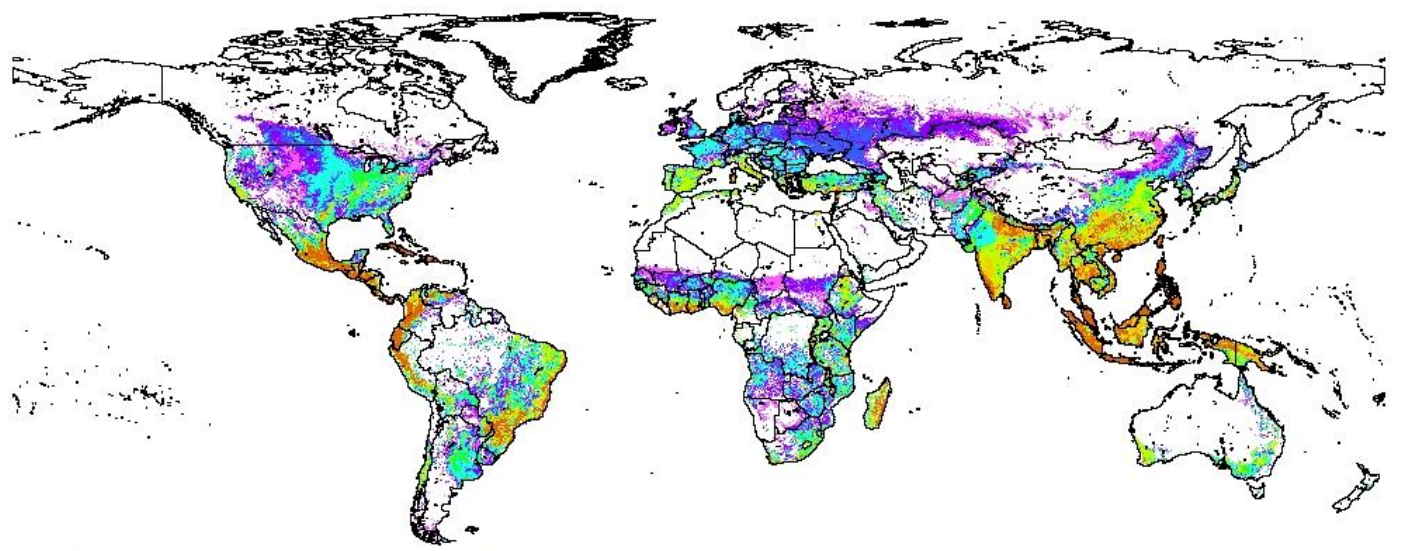

Amphibians impacts due to agriculture land use (Species eq. lost*years)

85

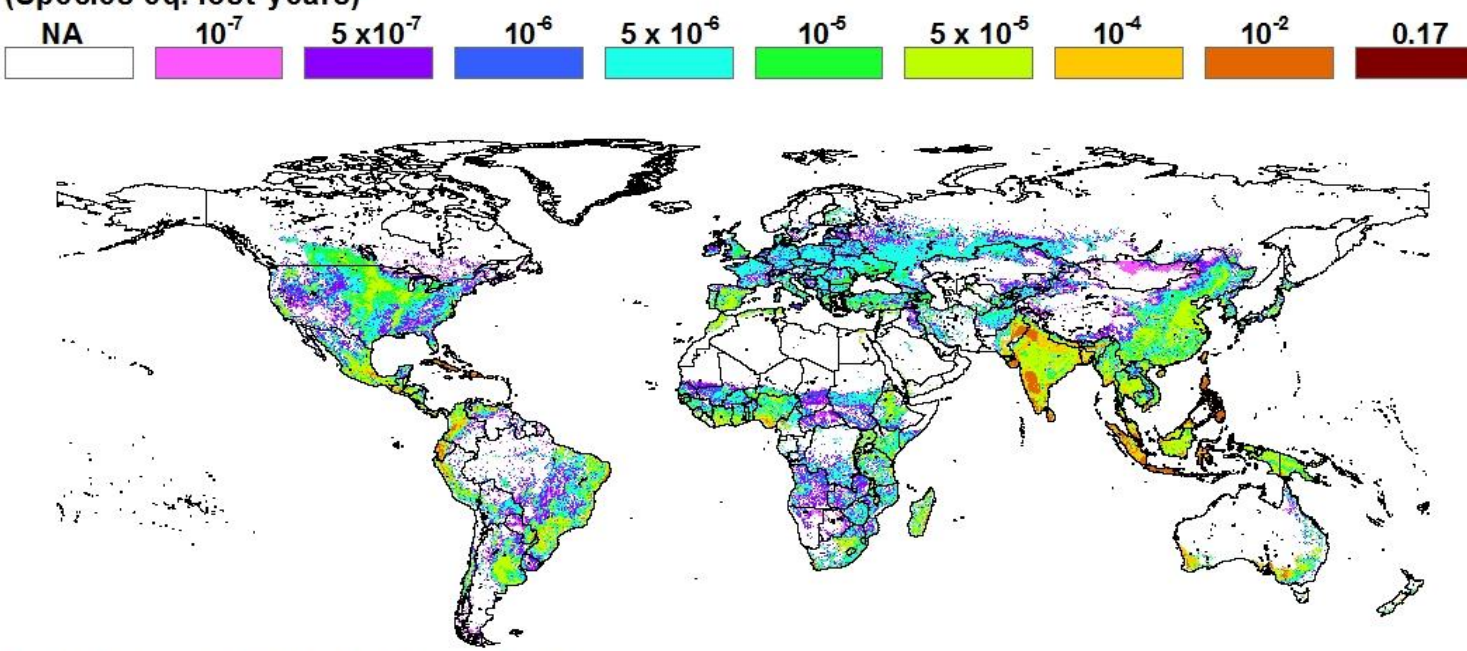

Birds impacts due to agriculture land use (Species eq. lost*years) 


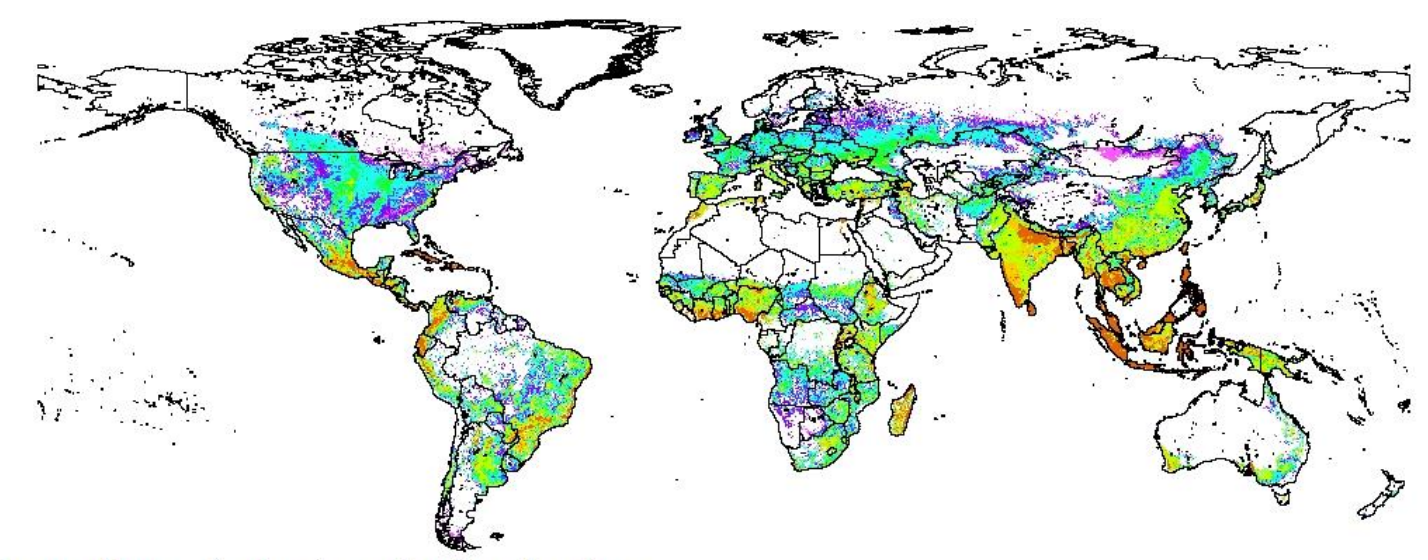

Mammal impacts due to agriculture land use

(Species eq. lost*years)

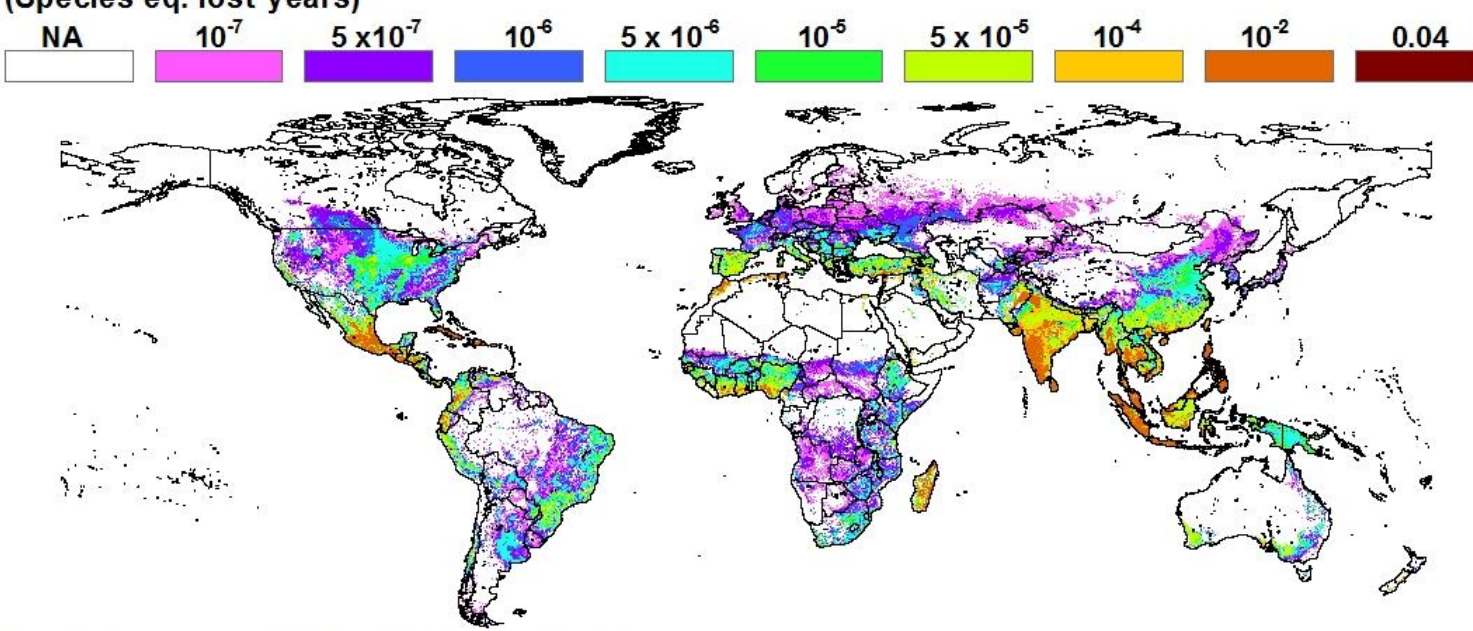

Reptiles impacts due to agriculture land use (Species eq. lost ${ }^{*}$ years)

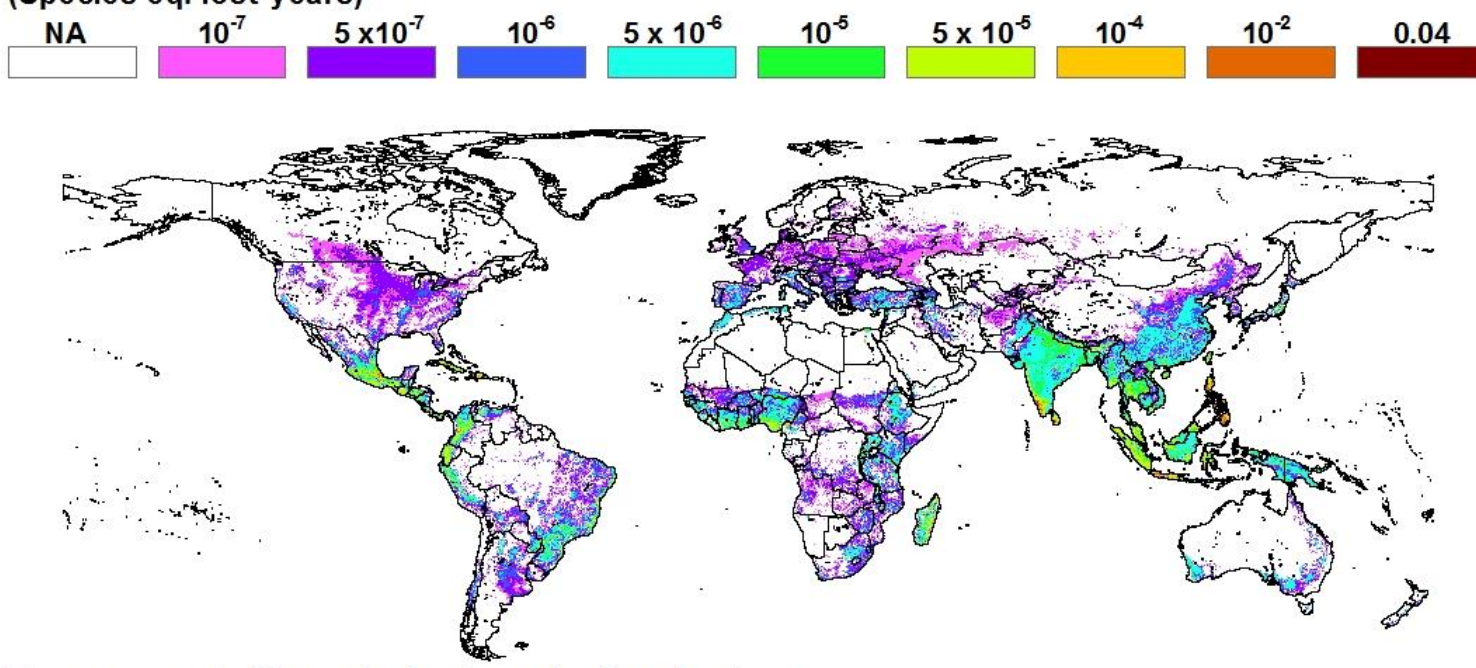

Taxa-aggregated impacts due to agriculture land use

(Potentially disappeared fraction*years) 
Figure S2. Biodiversity impacts per taxa (Species eq. lost*years) at 5 arc minute

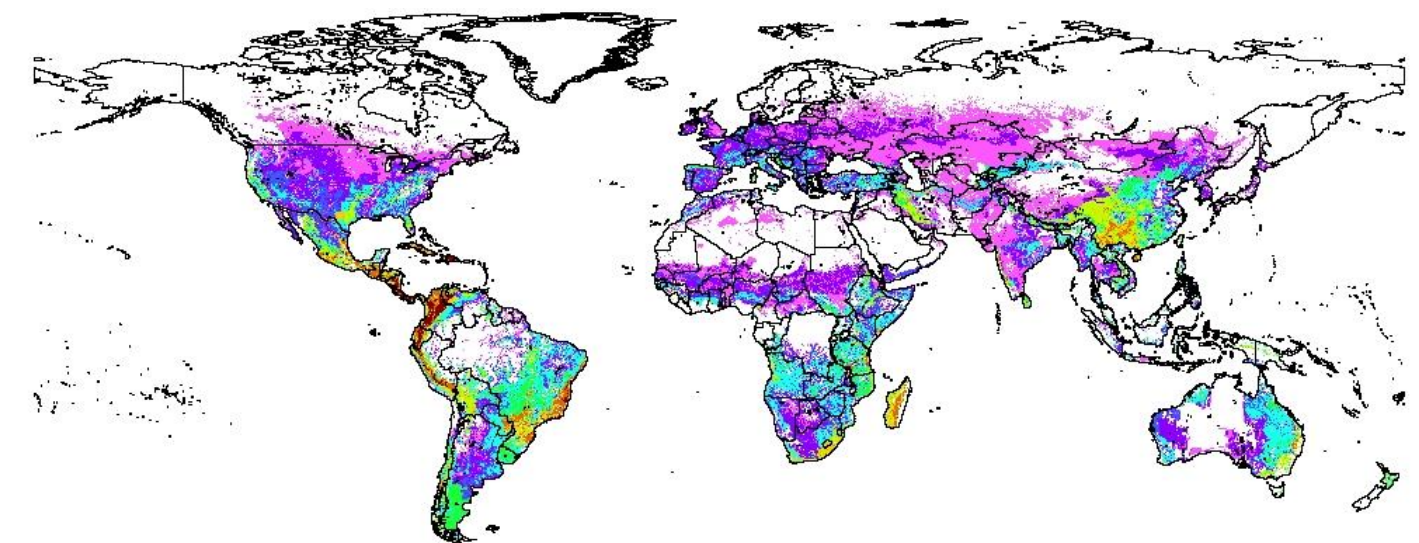

Amphibians impacts due to pasture land use

(Species eq. lost* years)
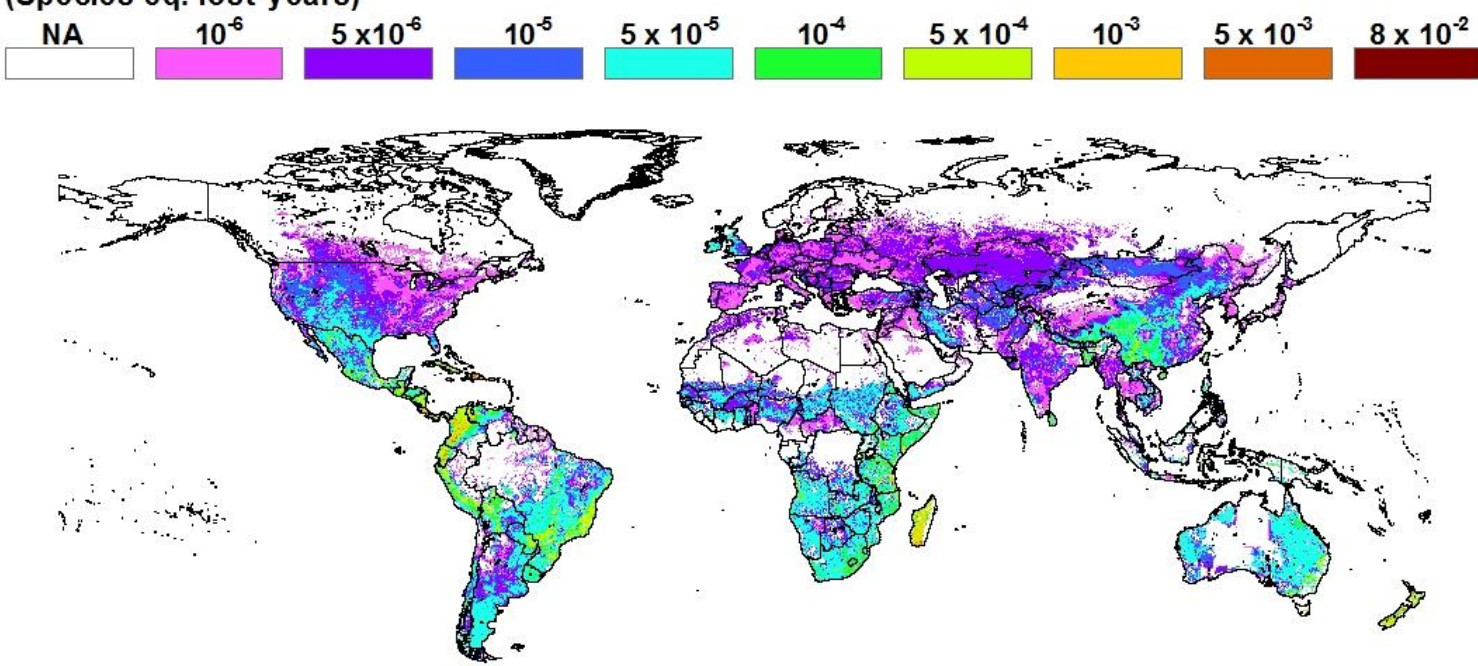

Birds impacts due to pasture land use (Species eq. lost* years) 


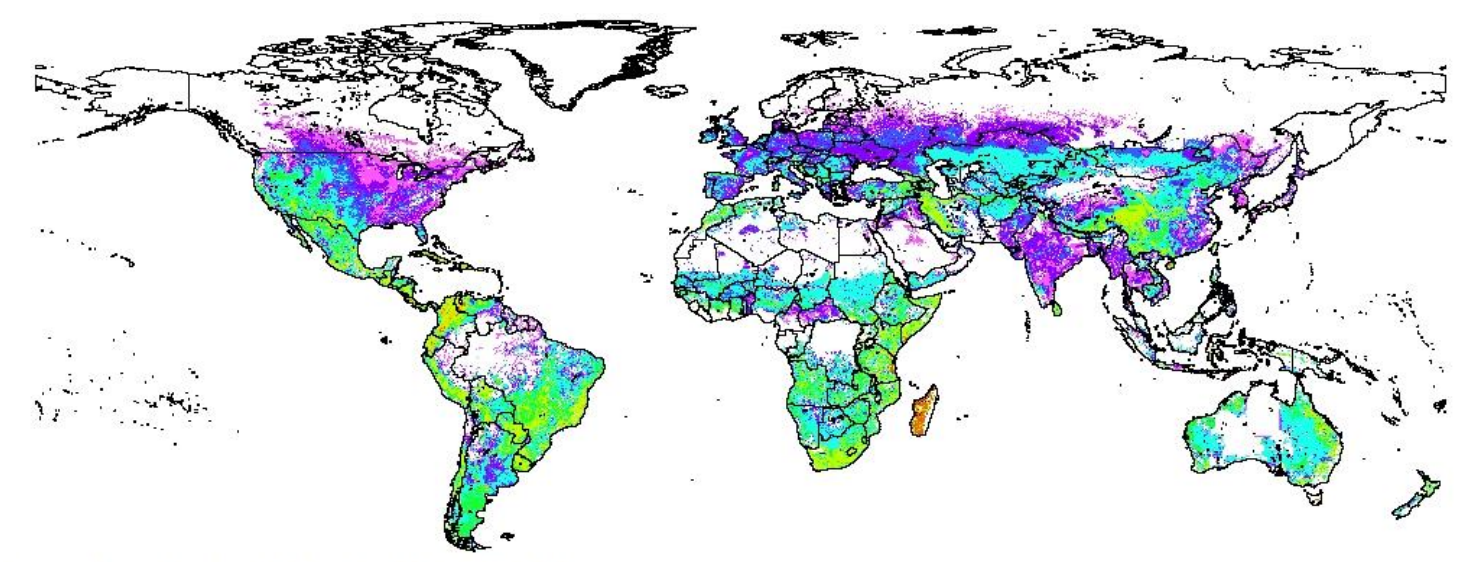

Mammal impacts due to pasture land use (Species eq. lost $t^{\star}$ ears)

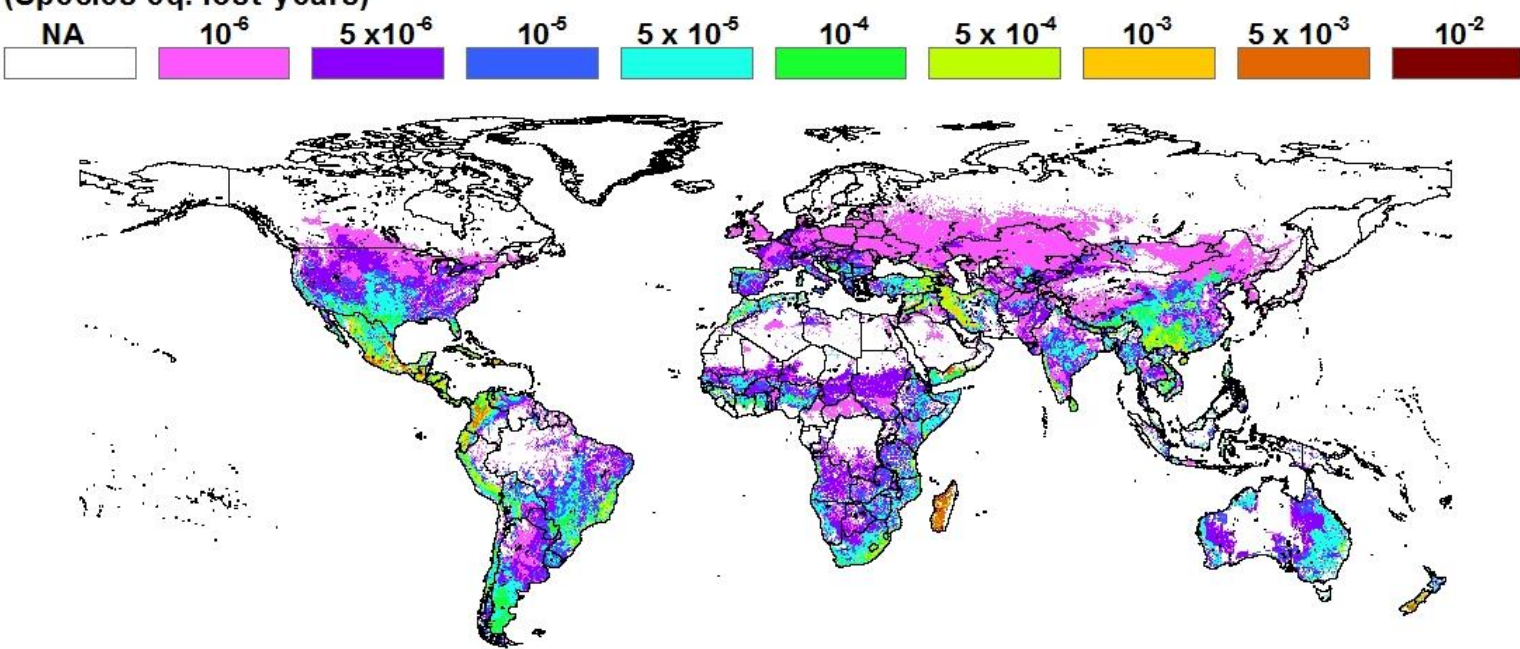

Reptiles impacts due to pasture land use (Species eq. lost*years)

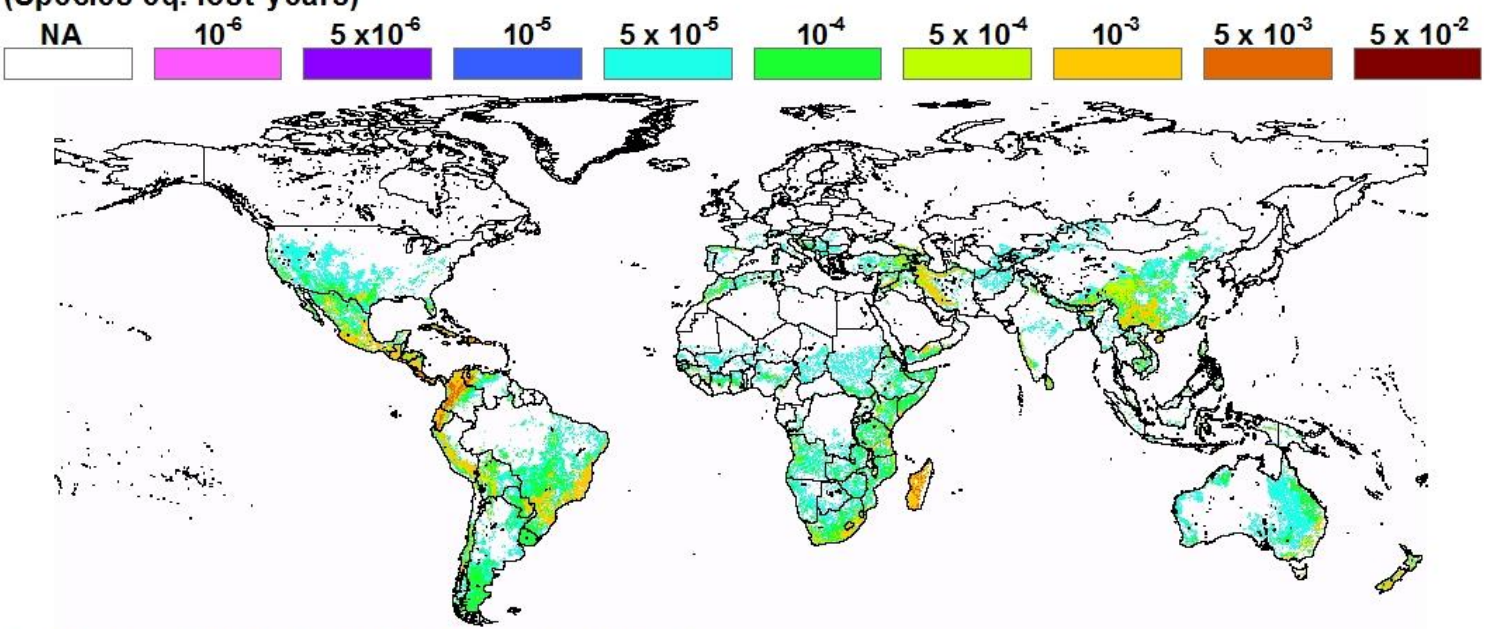

Taxa-aggregated impacts due to pasture land use (Potentially disappeared fraction*years) 
Figure S3. Biodiversity impacts per taxa (Species eq. lost*years) at 5 arc minute

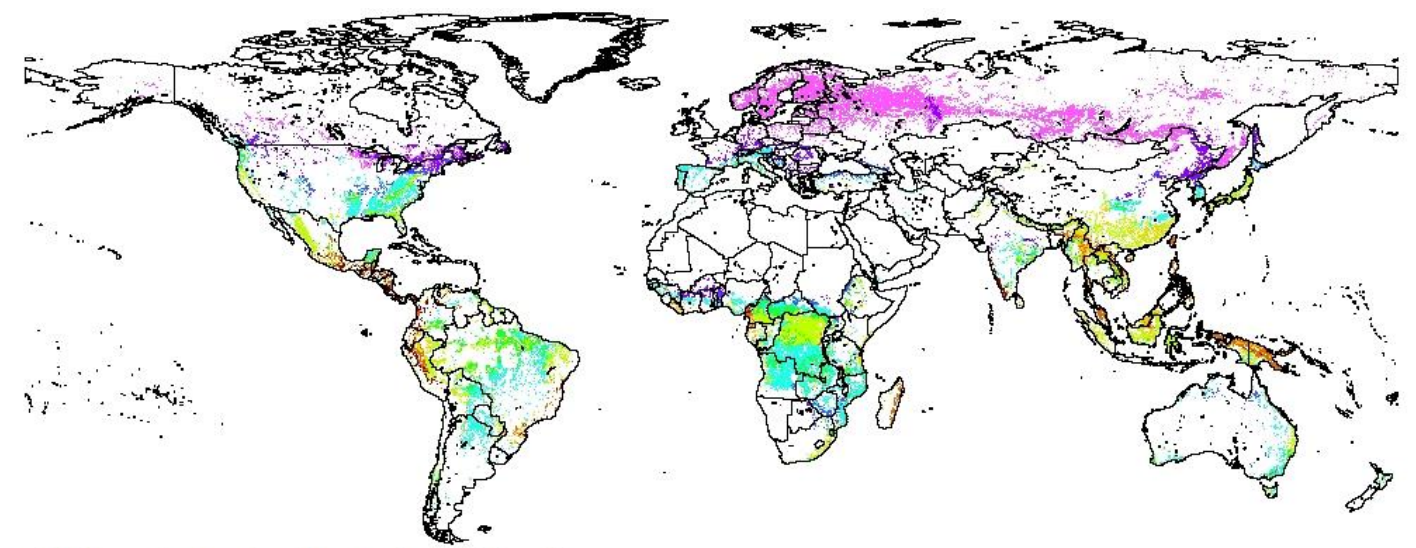

Amphibians impacts due to forest land use

(Species eq. lost*years)

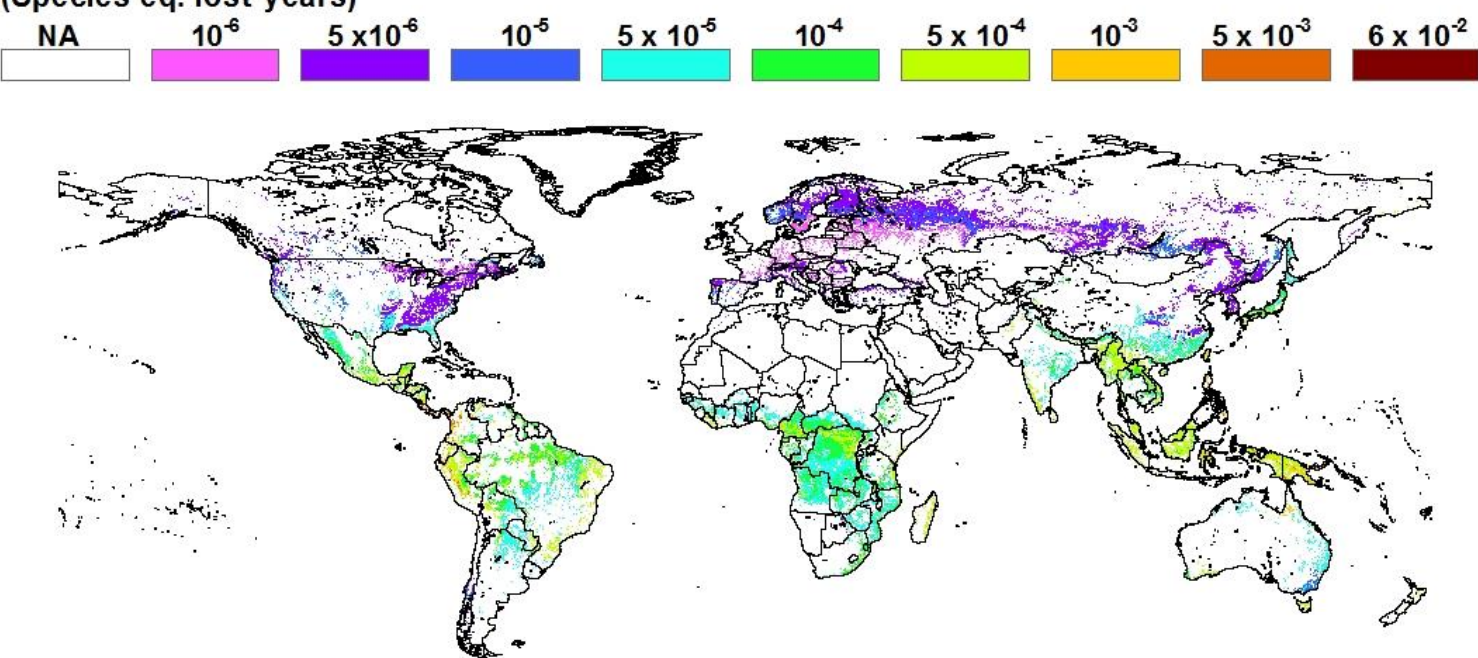

Birds impacts due to forest land use (Species eq. lost*years)

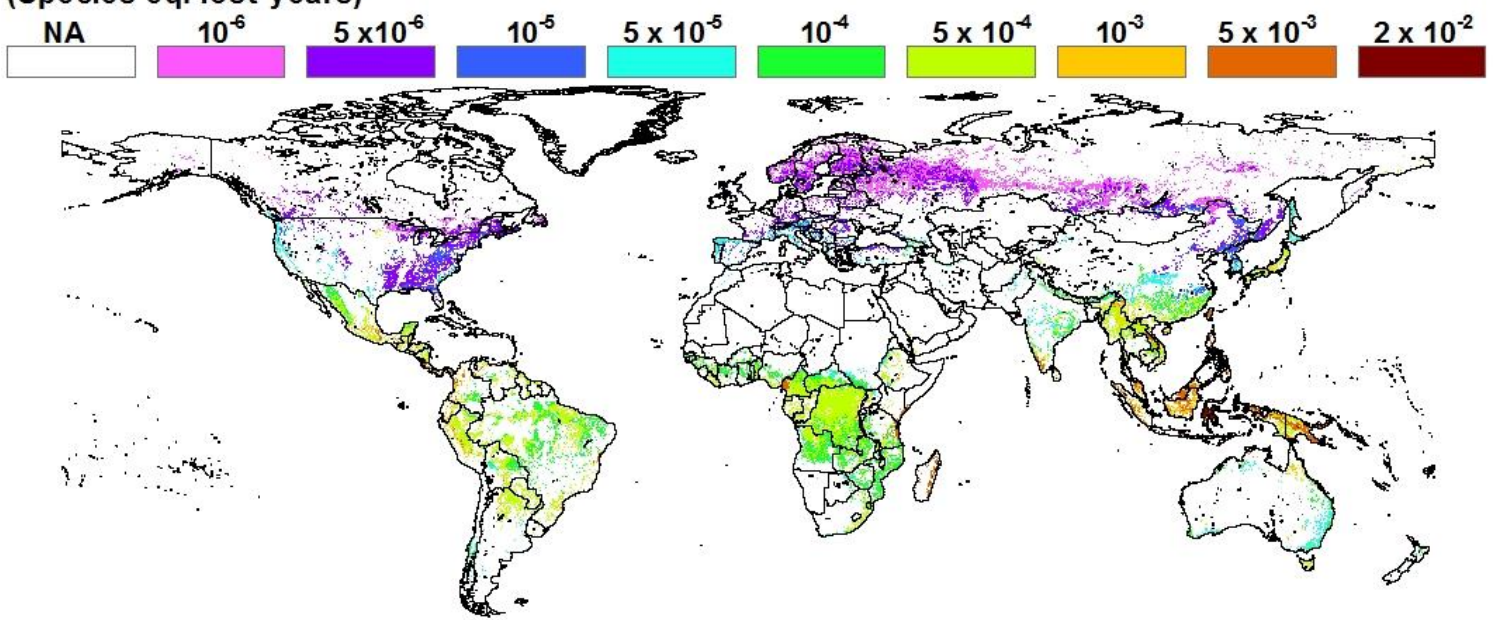

Mammal impacts due to forest land use (Species eq. lost* years)

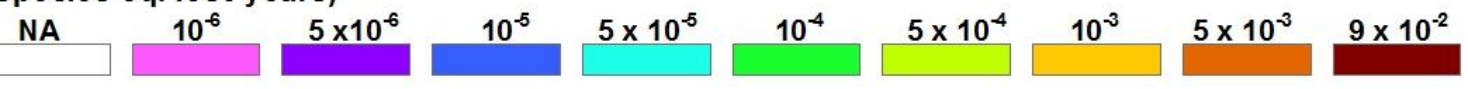




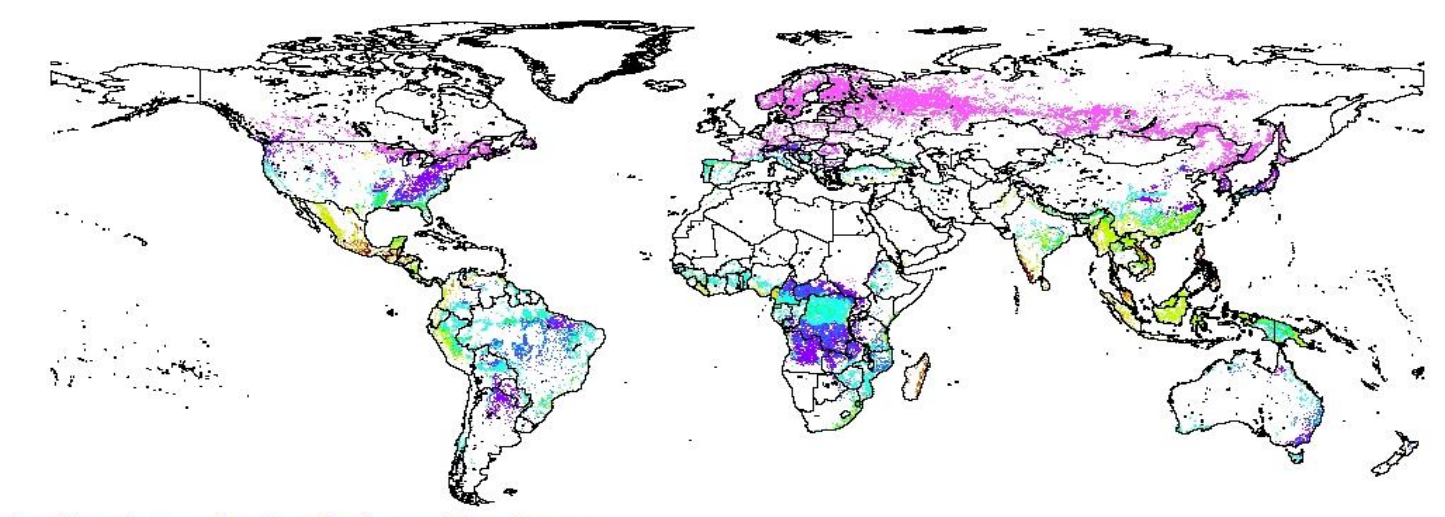

Reptiles impacts due to forest land use

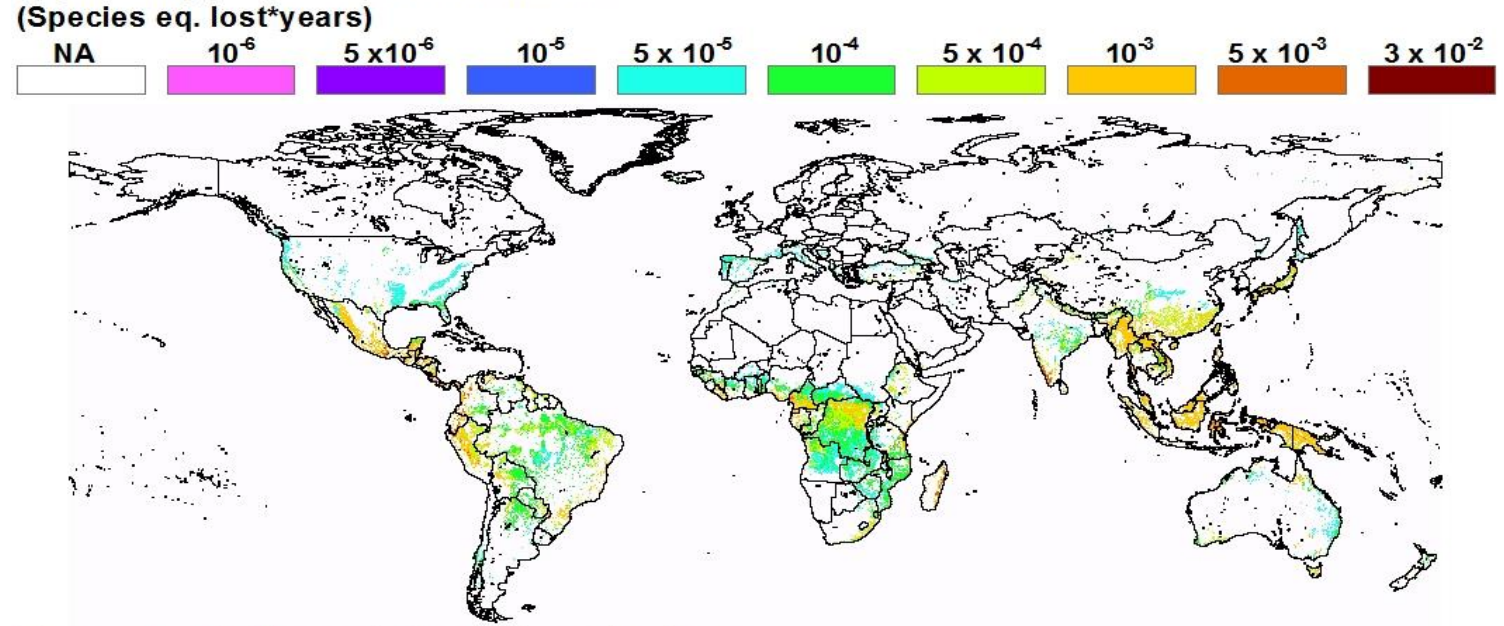

Taxa-aggregated impacts due to forest land use

(Potentially disappeared fraction*years)

\section{Part C: References}

Chaudhary, A., Verones, F., de Baan, L., \& Hellweg, S. Quantifying Land Use Impacts on Biodiversity: Combining Species-Area Models and Vulnerability Indicators. Environ. Sci. Technol. 2015, 49(16), 9987-9995.

Olson, D.; Dinerstein, E.; Wikramanayake, E.; Burgess, N.; Powell, G.; Underwood, E.; D’Amico, J.; Itoua, I.; Strand, H.; Morrison, J.; Loucks, C.; Allnutt, T.; Ricketts, T.; Kura, Y.; Lamoreux, J.; Wettengel, W.; Hedao, P.; Kassem, K. Terrestrial ecoregions of the worlds: A new map of life on Earth. BioScience 2001, 51 (11), 933- 938.

de Baan, L.; Mutel, C. L.; Curran, M.; Hellweg, S.; Koellner, T. Land use in life cycle assessment: global characterization factors based on regional and global potential species extinction. Environ. Sci. Technol. 2013, 47 (16), 9281-9290.

IUCN, IUCN Red List Categories and Criteria version 3.1. Cambridge: IUCN Species Survival Commission, 2001.

5 Verones, F.; Huijbregts, M. A.; Chaudhary, A.; de Baan, L.; Koellner, T.; Hellweg, S. 